MALARIA

JOURNAL

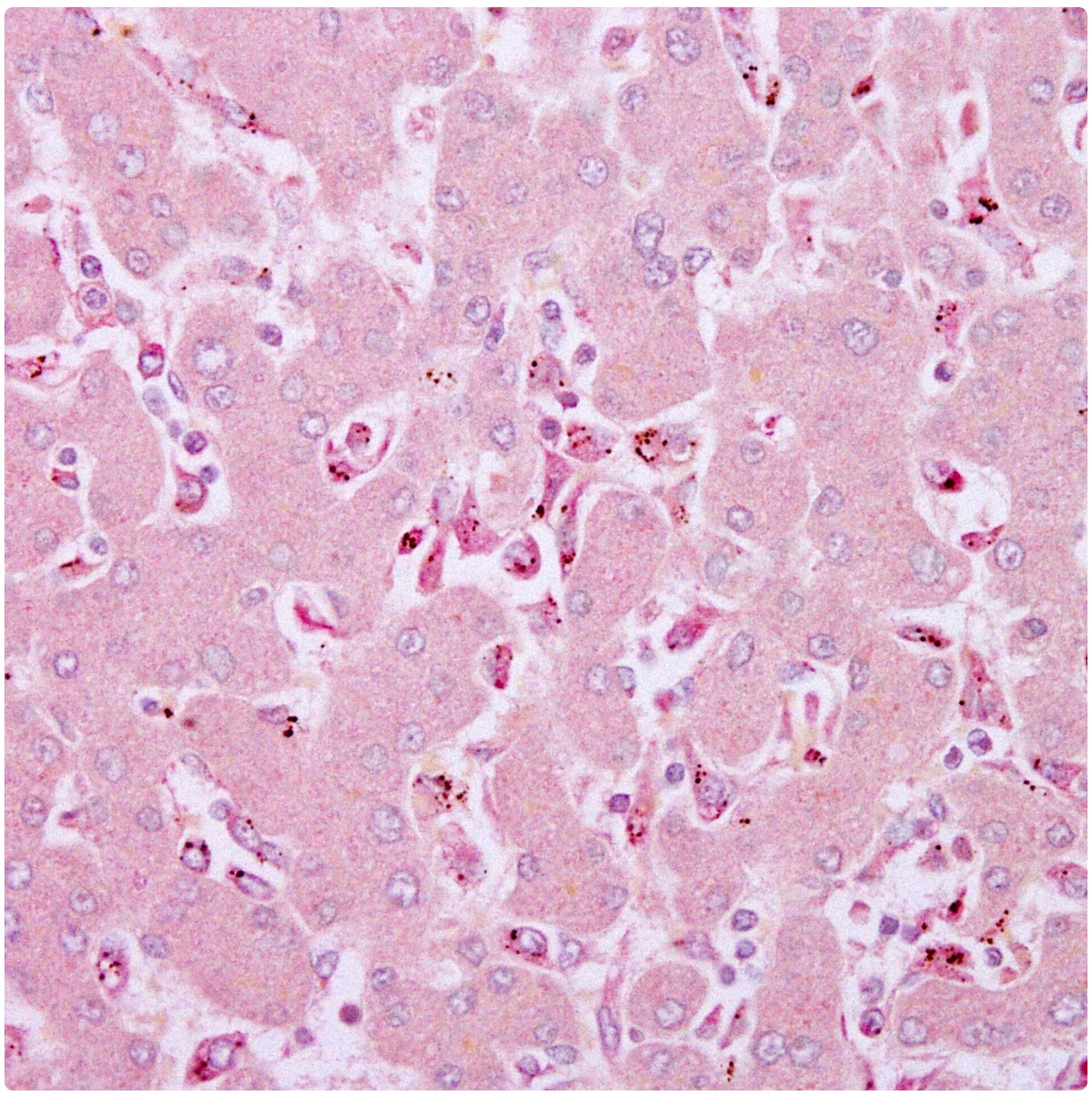

Liver changes in severe Plasmodium falciparum malaria: histopathology, apoptosis and nuclear factor kappa B expression

Viriyavejakul et al. 


\title{
Liver changes in severe Plasmodium falciparum malaria: histopathology, apoptosis and nuclear factor kappa B expression
}

\author{
Parnpen Viriyavejakul ${ }^{1,2^{*}}$, Vasant Khachonsaksumet ${ }^{1}$ and Chuchard Punsawad $^{3}$
}

\begin{abstract}
Background: Liver involvement in severe Plasmodium falciparum infection is commonly a significant cause of morbidity and mortality among humans. The clinical presentation of jaundice often reflects a certain degree of liver damage. This study investigated the liver pathology of severe $P$. falciparum malaria as well as the regulation and occurrence of apoptosis in cellular components of formalin-fixed, paraffin-embedded liver tissues.

Methods: The liver tissues used in the study came from patients who died from $P$. falciparum malaria with hyperbilirubinaemia (total bilirubin (TB) $\geq 51.3 \mu \mathrm{mol} / \mathrm{L}$ or $3 \mathrm{mg} / \mathrm{dl}$ ) (12 cases), P. falciparum malaria without hyperbilirubinaemia (TB < $51.3 \mu \mathrm{mol} / \mathrm{L})(10$ cases); and patients who died due to accidents, whose liver histology was normal (the control group) (10 cases). The histopathology of the liver tissue was studied by routine histology method. Caspase-3 and nuclear factor kappa B (NF-kB) p65 expressions were determined using immunohistochemistry.

Results: The severity of liver histopathology, occurrence of apoptosis and NF-kB p65 activation in P. falciparum malaria were associated with higher TB level. Significant correlations were found between NF-KB p65 expression and apoptosis in Kupffer cells and lymphocytes in the portal tracts.

Conclusions: Hyperplastic Kupffer cells and portal tract inflammation are two main features found in the liver tissues of severe $P$. falciparum malaria cases. In addition, NF-KB is associated with Kupffer cells and lymphocyte apoptosis in severe P. falciparum malaria.
\end{abstract}

Keywords: Malaria, Plasmodium falciparum, Liver, Kupffer cells, Bilirubin, Nuclear factor kappa B, NF-kB p65, Cleaved caspase-3, Apoptosis, Immunohistochemistry

\section{Background}

Plasmodium falciparum malaria is a life-threatening infectious disease that remains a major global health problem. The severe manifestations often present clinically as cerebral malaria, pulmonary oedema, acute kidney injury, hypoglycaemia, lactic acidosis, anaemia and liver involvement [1]. Plasmodium falciparum malaria causes clinical jaundice in $2.5-5.3 \%$ of cases in endemic areas $[2,3]$. The liver is an important organ involved during the hepatic stage of the malaria parasite's life cycle, where malaria sporozoites develop into merozoites. The

\footnotetext{
* Correspondence: parnpen.vir@mahidol.ac.th

'Department of Tropical Pathology, Faculty of Tropical Medicine, Mahidol University, 420/6 Rajvithi Road, Bangkok 10400, Thailand

${ }^{2}$ Center for Emerging and Neglected Infectious Diseases, Mahidol University,

Salaya, Nakhon Pathom 73170, Thailand

Full list of author information is available at the end of the article
}

merozoites are then released into the circulation and enter the erythrocytic stage. In the erythrocytic stage, parasitized red blood cells (PRBCs) become sequestered in small blood vessels. The degraded haemozoin pigment is then engulfed by local tissue macrophages, such as Kupffer cells and alveolar macrophages. Common histopathological findings of the liver in P. falciparum malaria include reactive Kupffer cells, retention of haemozoin pigment and minimal PRBC sequestration [4,5]. An ultrastructural study reported an association between high PRBC load in the livers of malaria patients with jaundice, hepatomegaly and liver enzyme elevation [6].

Apoptotic changes occur in a variety of cellular systems and involve both physiologic and pathologic changes. While apoptotic change in the liver have not been documented in human malaria, changes have been 
reported in animal models during the erythrocytic stage in hepatocytes $[7,8]$ and during the hepatic stage in Kupffer cells [9]. This process of programmed cell death can be mediated by various stimuli, including hormones, cytokines, growth factors, bacterial or viral infections and the immune response [10]. Cell apoptosis is regulated via two major pathways: the intrinsic or mitochondrial pathway and the extrinsic or death-receptor pathway. Initiator caspases, such as caspase- 8 or -9 , play a regulatory role by activating downstream effector caspases, such as caspase$3,-6$, or -7 [11]. NF-kB has been shown to regulate the apoptotic program in various cell types, either as an upregulating response or as an apoptosis blocker [12]. Evidence of NF- $\mathrm{kB}$ regulating apoptosis was found in the brain endothelial cells and intravascular lymphocytes in cerebral malaria [13]. However, no linkage between NF-kB and apoptosis has been reported in the livers of P. falciparum malaria patients. This study evaluated the liver pathology of severe $P$. falciparum malaria in association with total bilirubin (TB) level. The occurrence of apoptosis and its relation to a signaling molecule (NF- $\mathrm{kB}$ ) in liver tissues was investigated.

\section{Methods}

Liver tissue specimens from malaria patients and controls Specimens were classified into two groups according to the level of total bilirubin (TB): TB $\geq 51.3 \mu \mathrm{mol} / \mathrm{L}(3 \mathrm{mg} / \mathrm{dl})$ (12 cases) and TB $<51.3 \mu \mathrm{mol} / \mathrm{L}$ (10 cases), based on laboratory data. Liver specimens with normal histology obtained from fatal accident cases (10 cases), served as the control group. The specimens were obtained from autopsied cases at the Department of Tropical Pathology, Faculty of Tropical Medicine, Mahidol University, Bangkok, Thailand. Control cases came from the same region. Patients with hepatitis B co-infection, and patients with glucose-6-phosphate dehydrogenase (G6PD) deficiency, were excluded from the study. The use of left-over liver specimens and the study protocol were reviewed and approved by the Ethics Committee of the Faculty of Tropical Medicine, Mahidol University (MUTM 2011-025-01 and MUTM 2011-025-02).

\section{Liver tissue preparation}

Left-over liver tissues in paraffin-embedded blocks were re-embedded with new paraffin medium using standard histological techniques. Liver tissues were sectioned at $4 \mu \mathrm{m}$ thickness and placed onto glass slides for histopathological examination and onto positively charged slides for immunohistochemistry study against cleaved caspase- 3 and NF-kB p65.

\section{Histology of liver in severe $P$. falciparum malaria}

Overall liver histopathology was classified based on the severity of six histological criteria, namely fatty change, hyperplastic Kupffer cells, portal tract inflammation, bile duct proliferation, sinusoidal congestion and haemozoin deposition. Quantification was performed under high (400x) magnification. The severity level of each histopathological change was graded on a scale from 0 to 3, according to semi-quantitative assessment (Table 1). The highest possible total score was 18 (6 histological criteria $\mathrm{x} 3$ as highest scale). Score 0 meant no histopathological change and score 18 referred to most severe histopathological change. Microscopic evaluation was done by two observers (PV and $\mathrm{CP}$ ). A third person was asked to score the histopathological changes if more than 2 grading variations were observed.

\section{Immunohistochemical staining of cleaved caspase-3 and NF-KB p65}

The $4 \mu \mathrm{m}$ paraffin sections were deparaffinized and rehydrated by sequential immersion in a graded series of alcohol, then transferred into water for 5 mins. To inhibit endogenous peroxidase activity, the sections were incubated with $3 \% \mathrm{H}_{2} \mathrm{O}_{2}$ for 5 mins. The sections were then heated in a microwave oven (in $0.1 \mathrm{M}$ sodium citrate buffer, $\mathrm{pH} 6.0$ for cleaved caspase- 3 and $0.1 \mathrm{M}$ Tris- $\mathrm{HCl}$ buffer, $\mathrm{pH} 9.0$ for NF-kB p65) for 20 mins for epitope retrieval. After washing with phosphate buffered saline (PBS), pH 7.4, sections were incubated for 30 mins with normal serum as blocking solution to reduce the nonspecific background, then cooled to room temperature while still immersed in buffer. The following protocol was

Table 1 Histopathological changes and grading schemes used to evaluate liver tissues

\begin{tabular}{ccccc}
\hline Histopathologic & \multicolumn{4}{c}{ Histopathologic grading } \\
\cline { 2 - 5 } changes & $\mathbf{0}$ & $\mathbf{1}$ & $\mathbf{2}$ & $\mathbf{3}$ \\
\hline Fatty change & No fatty change & $<10 \%$ & $30 \%$ & $>50 / \mathrm{HPF}$ \\
Kupffer cells/HPF & $<20 / \mathrm{HPF}$ & $20-35 / \mathrm{HPF}$ & $36-50 / \mathrm{HPF}$ & $>30 \%$ of portal tract area \\
Portal tract inflammation & $<5 \%$ of portal tract area & $5-15 \%$ of portal tract area & $16-30 \%$ of portal tract area & Severe proliferation \\
Bile duct proliferation & No proliferation & Mild proliferation & Moderate proliferation & Severe congestion \\
Sinusoid congestion & No congestion & Mild congestion & Moderate congestion & Severe deposition \\
Haemozoin deposition & No deposition & Mild deposition & Moderate deposition & \\
\hline
\end{tabular}

$\mathrm{HPF}=$ high power field (magnification 400x). 
realized using avidin-biotin alkaline phosphatase complex (VECTASTAIN $^{\circledR}$ ABC-AP kit (Rabbit IgG) \# AK-5001) for cleaved caspase 3 and avidin-biotin peroxidase complex (VECTASTAIN ${ }^{\circledR}$ ABC kit (Mouse IgG) \# PK-4002) for NF-kB p65 (Vector Laboratories, Inc., USA) according to the manufacturer's protocol. The sections were incubated with primary antibody; rabbit polyclonal anticleaved caspase-3 (Asp175) antibody (1:200 dilution) (Cell Signaling Technology, USA) and mouse monoclonal antiNF-кB p65 (1:50 dilution) (Santa Cruz Biotechnology Inc., Santa Cruz, CA) and incubated overnight at $4{ }^{\circ} \mathrm{C}$ in a humidity chamber. The following day, sections were washed three times with PBS, and incubated with anti-mouse/ rabbit biotinylated secondary antibody (Vector Laboratories, Inc., USA) for 30 mins at room temperature and reacted with avidin-biotin complex $(\mathrm{ABC})$ conjugated with alkaline phosphatase (AP)/horseradish peroxidase (HRP) (Vector Laboratories, Inc., USA) for 30 mins. After washing, enzyme activity was visualized by Vector ${ }^{\circledR}$ Red substrate kit (Vector Laboratories, Inc., USA) for cleaved caspase-3, resulting in the formation of a red colour at the antigen sites and by 3,3'- diaminobenzidine (DAB) (Vector Laboratories, Inc., USA) for NF-kB p65, presenting as a brown colour. Subsequently, sections were counterstained with haematoxylin for $1 \mathrm{~min}$, and mounted with a coverslip.

\section{Cleaved caspase- 3 and NF-KB p65 analysis}

The presence of immunopositive cells for cleaved caspase- 3 and NF- $\mathrm{KB}$ p 65 was recorded as percentages. In addition, immunostaining intensity was scored from 0-3 (0-negative staining, 1- mild, 2- moderate, and 3strong immunostaining). Total score was calculated by multiplying percentage immunopositive cells and intensity, a method used by Punsawad et al. 2013 [13].

\section{Measurement of Kupffer cell length}

Ten representative views of H\&E-stained liver sections were randomly photographed at 400x magnification using an Olympus Bx41 light microscope (Olympus, Tokyo, Japan) connected to an Olympus DP20 digital camera (Olympus, Tokyo, Japan). Kupffer cell length was measured with the UTHSCSA Image Tool program (developed at the University of Texas Health Science Center at San Antonio, TX; freely available from the Internet).

\section{Statistical analysis}

Data were expressed as mean \pm standard error of the mean (SEM). The normality of distribution was determined by the Kolmogorov-Smirnov test. Differences between groups were analyzed by Mann Whitney $U$-test. In addition, the correlations of each variable within groups and pertinent clinical data were calculated using Spearman's rank correlation $\left(r_{s}\right)$. Statistical analysis was performed using SPSS version 17.0 software (SPSS, IL, USA). A $p$ value $<0.05$ was considered significantly different.

\section{Results}

\section{Malaria patients}

Twenty-two liver specimens were collected from $P$. falciparum malaria cases, consisting of 12 cases with hyperbilirubinaemia (total bilirubin $(\mathrm{TB}) \geq 51.3 \mu \mathrm{mol} / \mathrm{L}$ or $3 \mathrm{mg} / \mathrm{dl}$ ) and 10 cases without hyperbilirubinaemia $(\mathrm{TB}<51.3 \mu \mathrm{mol} / \mathrm{L})$. Ten cases with normal liver histopathology served as controls. Table 2 summarizes the mean age, sex, days of fever pre-admission, parasitaemia and important liver function tests of the malaria patients. Significant differences between two groups were noted in the levels of albumin, aspartate aminotransferase (AST), alanine aminotransferase (ALT), alkaline phosphatase, total and direct bilirubin $(p$ value $<0.05)$. Common associated complications were cerebral malaria (70.00\% for non-hyperbilirubinaemia and $33.33 \%$ for hyperbilirubinaemia groups) and acute kidney injury (33.33\% for hyperbilirubinaemia group).

Table 2 Clinical and laboratory parameters of $\boldsymbol{P}$. falciparum malaria patients

\begin{tabular}{|c|c|c|}
\hline & Non-hyperbilirubinaemia $(T B<51.3 \mu \mathrm{mol} / \mathrm{L})(\mathrm{n}=10)$ & Hyperbilirubinaemia $(T B \geq 51.3 \mu \mathrm{mol} / \mathrm{L})(\mathrm{n}=12)$ \\
\hline Age (years) $(p=0.974)$ & $25.8 \pm 3.95$ & $26.17 \pm 4.28$ \\
\hline $\operatorname{Sex}(M: F)$ & $6: 4$ & $10: 2$ \\
\hline Days of fever $(p=0.095)$ & $4.1 \pm 0.82$ & $5.83 \pm 0.77$ \\
\hline Parasitaemia $(/ \mu l)(p=0.619)$ & $303,186.67 \pm 151,070.30$ & $391,501.40 \pm 183,362.30$ \\
\hline Albumin $(g / L)(p=0.006)$ & $33.2 \pm 0.17$ & $25.3 \pm 0.13$ \\
\hline $\operatorname{AST}(\mathrm{U} / \mathrm{L})(p=0.006)$ & $72.00 \pm 21.41$ & $266.33 \pm 64.93$ \\
\hline $\operatorname{ALT}(U / L)(p=0.049)$ & $49.17 \pm 8.23$ & $126.79 \pm 29.22$ \\
\hline Alkaline phosphatase $(U / L)(p=0.049)$ & $8.42 \pm 2.62$ & $20.07 \pm 4.33$ \\
\hline Total bilirubin $(\mu \mathrm{mol} / \mathrm{L})(p=0.001)$ & $30.61 \pm 0.31$ & $441.60 \pm 5.39$ \\
\hline Direct bilirubin $(\mu \mathrm{mol} / \mathrm{L})(p=0.001)$ & $8.55 \pm 0.15$ & $217.17 \pm 2.73$ \\
\hline
\end{tabular}




\section{Histopathology of liver in severe $P$. falciparum malaria}

Figure 1 displays histopathological changes of the liver in severe P. falciparum malaria. Morphologically, hepatocytes and endothelial cells (ECs) in the liver were generally unaffected in severe P. falciparum malaria. Fatty change and bile duct proliferation were not features of $P$. falciparum infection. Hyperplastic Kupffer cells, portal tract inflammation, sinusoidal congestion and haemozoin pigment deposition were important pathological hallmarks related to higher TB levels (Table 3). The total histopathological grading score showed the overall changes and was found to be highest among the group of malaria patients with hyperbilirubinaemia (12/18). Figure 1 (A-C) illustrates a normal portal tract, consisting of hepatic vein, hepatic artery, and bile duct, with surrounding hepatocytes. Very few inflammatory cells are noted within the portal tract. Minimal fatty change is sometimes observed (Figure 1C). Liver tissues from malaria patient without hyperbilirubinaemia show enlarged sinusoidal area, haemozoin pigment within the hyperplastic Kupffer cells, and inflammatory cells within the portal tract (Figure 1, D-F). In hyperbilirubinaemia group (Figure 1, G-I), liver tissues show dense inflammatory cells infiltration in the portal tract. At higher magnification, hyperplastic Kupffer cells are visible and contain haemozoin pigment. Sinusoidal areas are often congested. Central vein contains numerous PRBCs.

Fatty change, hyperplastic Kupffer cells and portal tract inflammation were quantified in each group (Table 4). There was no significant difference between fatty changes in the livers of the $P$. falciparum malaria groups and the normal controls (all $p>0.05$ ). However, hyperplastic Kupffer cells and portal tract inflammation were significantly higher in the malaria groups compared with the normal controls and highest in the livers of the P. falciparum patients with hyperbilirubinaemia. The number of hyperplastic Kupffer cells were increased in the malaria group with hyperbilirubinaemia (52.21 \pm 2.32/high power field (HPF)), compared with the normal liver group $(9.65 \pm 0.67 / \mathrm{HPF})(p<0.001)$ and the malaria group without hyperbilirubinaemia $(32.05 \pm 3.34 / \mathrm{HPF})$ $(p<0.001)$. Generally, Kupffer cell contains packed haemozoin pigment within the cytoplasm. Positive correlations were evident between $\mathrm{TB}$ and the number of Kupffer cells $\left(r_{s}=0.551, p=0.018\right)$ and between TB and \% lymphocytes in the portal tract $\left(r_{s}=0.743\right.$. $p=$ 0.020). In terms of Kupffer-cell length (Figure 2), the size of Kupffer cells as measured and analysed by Image Tool software showed significant numbers of reactive Kupffer cells in the malaria group with hyperbilirubinaemia (more

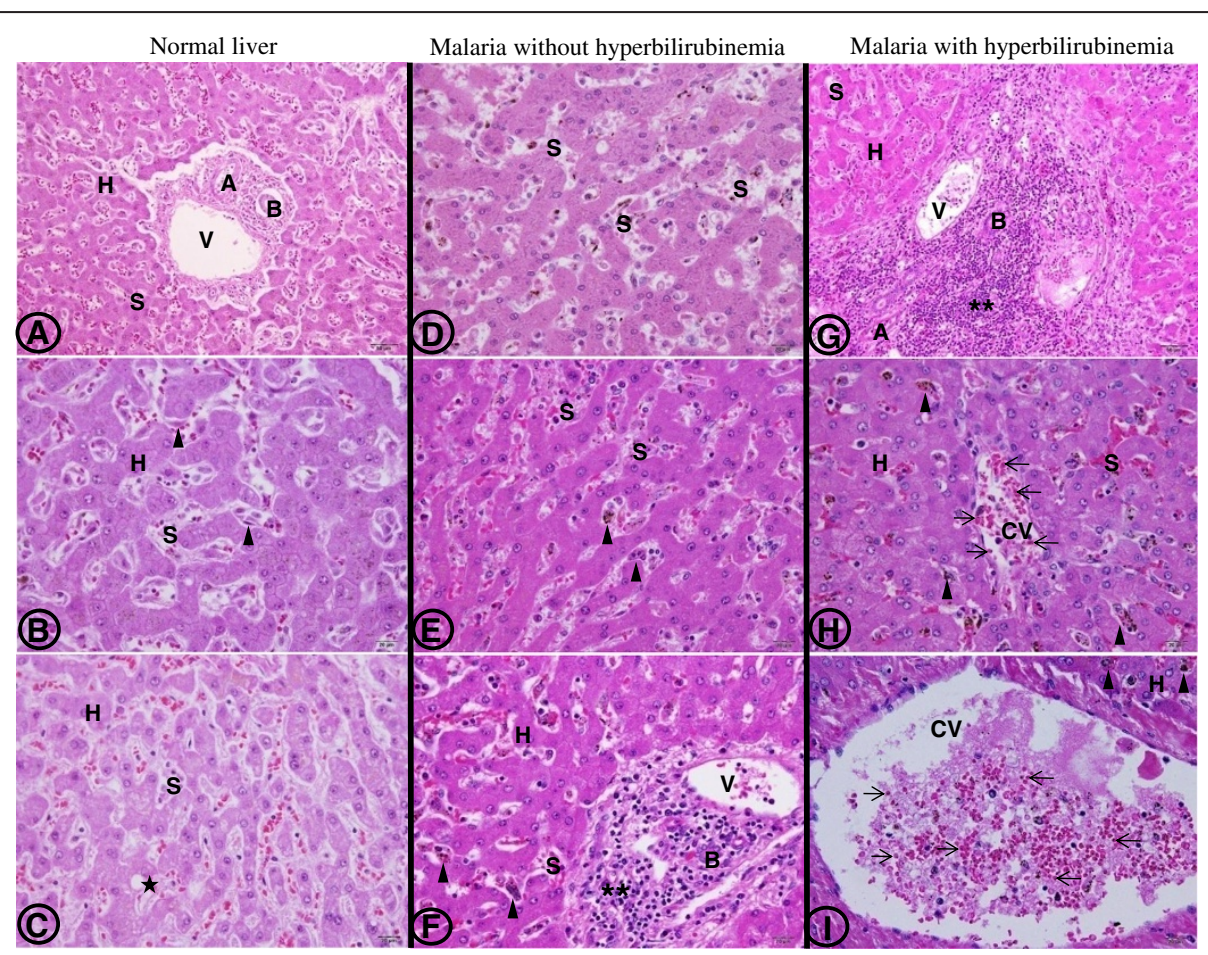

Figure 1 Histopathological changes of liver tissue from normal controls (A-C), from severe $P$. falciparum malaria patients without hyperbilirubinaemia (D-F) and from severe $P$. falciparum malaria patients with hyperbilirubinaemia (G-I). Images $A$ and $G$ are shown at 200x magnification; bars are $50 \mu \mathrm{m}$. Other images are at 400x magnification; bars are $20 \mu \mathrm{m}$. H- hepatocytes, A- hepatic artery, V- hepatic vein, B- bile duct, S- sinusoidal area, CV-central vein, arrowheads- Kupffer cells, star- fatty change, asterisks- inflammatory cells, arrows- PRBCs. 
Table 3 Histopathologic grading of liver tissues in P. falciparum malaria

\begin{tabular}{cccc}
\hline \multirow{2}{*}{$\begin{array}{c}\text { Histopathologic } \\
\text { changes }\end{array}$} & \multicolumn{3}{c}{ Histopathologic grading } \\
\cline { 2 - 4 } & Normal liver & Non-hyperbilirubinaemia (TB $<\mathbf{5 1 . 3} \boldsymbol{\mu m o l / L )}$ & Hyperbilirubinaemia (TB $\geq \mathbf{5 1 . 3} \boldsymbol{\mu m o l / L )}$ \\
\hline Fatty change & 0 & 0 & 0 \\
Kupffer cells hyperplasia & 0 & 1 & 3 \\
Portal tract inflammation & 1 & 2 & 3 \\
Bile duct proliferation & 0 & 2 & 0 \\
Sinusoid congestion & 0 & 3 & 3 \\
Haemozoin deposition & 0 & $8 / 18$ & 3 \\
Total histological score & $1 / 18$ & & $12 / 18$ \\
\hline
\end{tabular}

than three times), compared with the normal liver group $(p<0.001)$ and the non-hyperbilirubinaemia group $(p<0.001)$.

Occurrence of apoptosis in the livers of severe $P$.

\section{falciparum malaria cases}

Apoptosis was evaluated using monoclonal antibody against cleaved caspase-3, the final apoptotic pathway. The occurrence of apoptosis in the hepatocytes was negligible even in the severe $P$. falciparum malaria with hyperbilirubinaemia group. Figure $3 \mathrm{~A}-\mathrm{C}$ illustrates the occurrence of apoptosis in the liver tissues of severe $P$. falciparum malaria cases, compared with the normal controls. Percentage apoptosis for Kupffer cells and lymphocytes within the portal tracts is shown in Figure 4. The data show that both Kupffer cell and lymphocyte apoptosis were significantly increased in group with severe $P$. falciparum malaria with hyperbilirubinaemia compared with the non-hyperbilirubinaemia groups ( $p=$ 0.030 and $p=0.009$, respectively) and the normal controls (all $p<0.001$ ) (Figure 4A and B). The Kupffer cells and lymphocytes in the non-hyperbilirubinaemia group also expressed significantly higher levels of apoptosis than the normal controls $(p=0.005$ and $p=0.073$, respectively). Since immunostaining intensity is an important factor in evaluating the degree of protein expression, a total score incorporating percentage apoptosis and immunostaining intensity was also used to compare apoptosis in the liver. The total scores for Kupffer cell and lymphocyte apoptosis are shown in Figure 4. A similar trend to the percentage data was observed.

NF-KB p65 expression in the livers of severe $P$. falciparum malaria

NF-kB p65 expression and apoptosis in the livers of severe $P$. falciparum malaria were investigated. NF-kB p65 expression in Kupffer cells and portal lymphocytes is shown in Figure 5. In both Kupffer cells and lymphocytes, NF-kB p65 expression was significantly increased in the group with severe $P$. falciparum malaria with hyperbilirubinaemia, compared with non-hyperbilirubinaemia group ( $p=0.030$ and $p=0.009$, respectively) and normal controls (all $p<0.001$ ). The malaria group without hyperbilirubinaemia showed significantly higher levels of NF-kB p65 expression in the Kupffer cells and lymphocytes than the normal controls $(p=0.005$ and $p=0.007$, respectively).

Correlation between apoptosis and NF-KB p65 expression A significant positive correlation was found between cleaved caspase- 3 and NF- $\mathrm{BB}$ p65 immunopositive cells in Kupffer cells $\left(r_{s}=0.713, p<0.001\right)$, and lymphocytes in the portal tracts $\left(r_{s}=0.741, p<0.001\right)$ (Figure 6). Both the expression of cleaved caspase- 3 and NF- $\mathrm{kB}$ p65 were positively correlated with TB (Kupffer cells: $r_{s}=0.707$, $p=0.001$ and $r_{s}=0.853, p<0.001$, respectively) (lymphocytes: $r_{s}=0.490, p=0.039$ and $r_{s}=0.636, p=0.008$, respectively). Hyperplastic Kupffer cells were positively correlated with cleaved caspase-3 $\left(r_{s}=0.617, p=0.001\right)$

Table 4 Quantification of fatty changes, hyperplastic Kupffer cells and portal inflammation in the livers of $P$. falciparum malaria patients compared with the control group

\begin{tabular}{lcc}
\hline Histopathological changes & $\begin{array}{c}\text { Normal liver } \\
(\mathbf{n}=\mathbf{1 0})\end{array}$ & $\begin{array}{c}\text { Non-hyperbilirubinaemia } \\
(\mathbf{T B}<\mathbf{5 1 . 3} \boldsymbol{\mu m o l / L )}(\mathbf{n}=\mathbf{1 0})\end{array}$ \\
\hline Fatty changes (\%/HPF) & $0.59 \pm 0.25$ & $1.71 \pm 0.46$ \\
Hyperplastic Kupffer cells (count/HPF) & $9.65 \pm 0.67$ & $32.05 \pm 3.34^{\mathrm{a}}$ \\
Portal tract inflammation (\%) & $5.49 \pm 1.20$ & $17.1 \pm 1.62^{\mathrm{a}}$ \\
\hline
\end{tabular}

${ }^{a}$ Significant difference compared with normal controls, ${ }^{b}$ Significant difference between malaria groups ( $p<0.05$ is considered statistically significant), Mann Whitney U-test. 


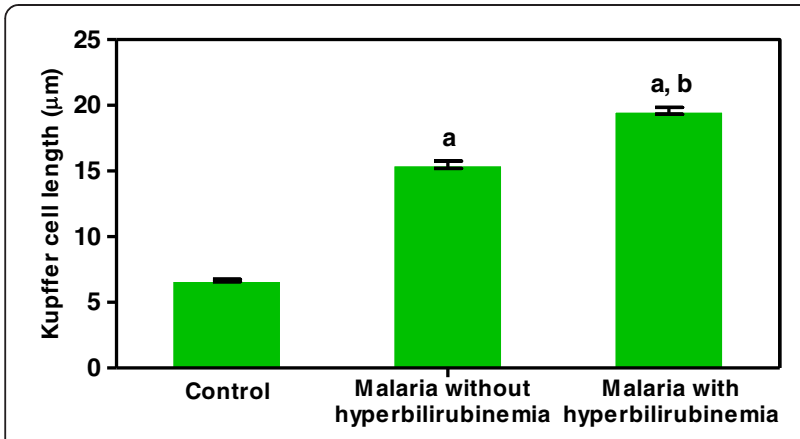

Figure 2 Length of Kupffer cells as measured and analyzed by Image Tool software. Significant differences in Kupffer cell length were observed between the severe malaria groups (with and without hyperbilirubinaemia) and the normal controls (a) and between the hyperbilirubinaemia and non-hyperbilirubinaemia groups $(b)(p<0.05)$. Data are presented as a mean \pm SEM.

and NF-kB p65 $\left(r_{s}=0.568, p=0.001\right)$ expression. The degree of portal tract inflammation was also positively correlated with cleaved caspase-3 $\left(r_{s}=0.612, p=0.001\right)$ and NF- $\mathrm{kB}$ p $65\left(r_{s}=0.519, p=0.002\right)$ expression. On the other hand, no significant association was seen between both NF- $\mathrm{kB}$ p65 and cleaved caspase-3 expression of Kupffer cells and portal lymphocytes, and clinical data (age, sex, days of fever pre-admission, parasitaemia and important liver function tests.

\section{Discussion}

\section{Liver pathology in severe $P$. falciparum malaria}

The present study shows a rise in liver transaminases and alkaline phosphatase in the malaria group with hyperbilirubinaemia $(\mathrm{TB} \geq 51.3 \mu \mathrm{mol} / \mathrm{L})$. Clinical jaundice in P. falciparum can be caused by several factors, i.e. intravascular haemolysis from parasitized red blood cells (PRBCs), G6PD deficiency-related haemolysis or antimalarial drugs, disseminated intravascular coagulation (DIC) or co-existing septicaemia-induced hepatitis [14,15]. The histopathology of the liver in severe malaria has been previously studied. However, the present study demonstrated certain morphological variations in the liver from other reports, such as an abundant chronic inflammatory cell response and an absence of liver cell necrosis. Liver changes in severe malaria often include hyperplastic Kupffer cells [4,5,16-18], fatty change [16,17], portal tract inflammation [17], cholestasis [16,17], liver cell necrosis $[4,16,18]$, sequestration of PRBCs and the deposition of haemozoin pigment $[4,5,16,18]$. The present study documented hyperplastic Kupffer cells with scattered haemozoin deposition and portal inflammation as the most common histological changes in the livers of severe P. falciparum malaria cases. The enlarged Kupffer cells were confirmed quantitatively using Image Tool software. The immune response in the liver to PRBCs primarily involves the activation of Kupffer cells. The recruitment and activation of Kupffer cells and macrophages in the spleen and bone marrow are important for the clearance of malaria parasites [19]. Portal tract inflammation consists mainly of lymphocytes and a few plasma cells (Table 4), in contrast with mild inflammation (portal and lobular lymphocytic infiltrates) reported earlier [5]. An acute inflammatory process involving neutrophils is not seen. The minimal fatty change

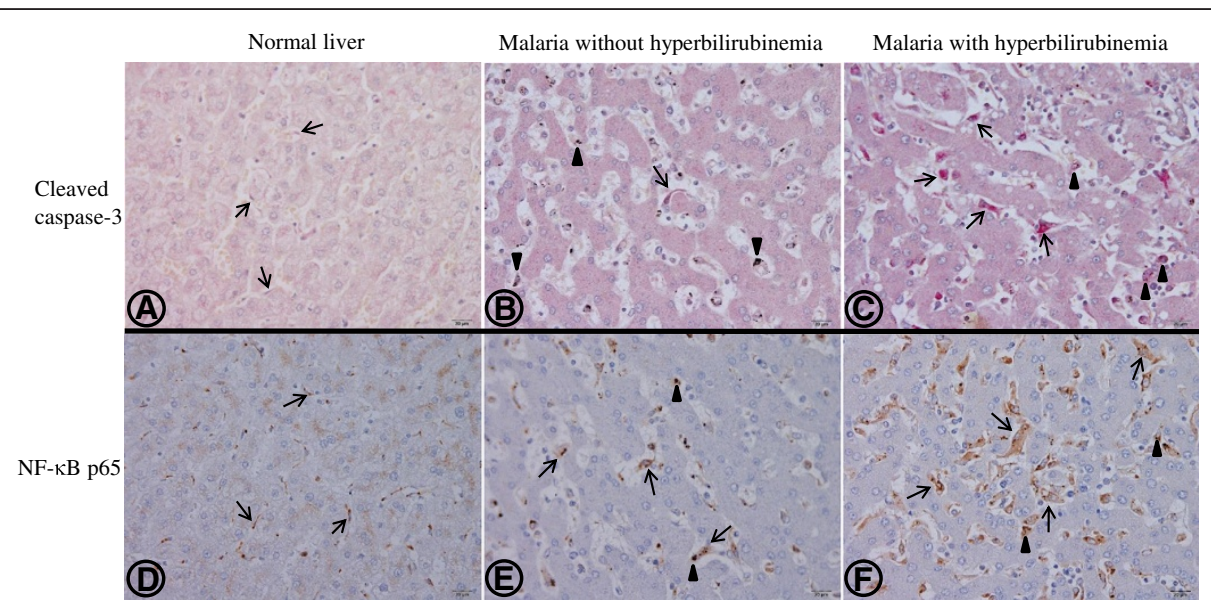

Figure 3 Representative immunohistochemical staining patterns of cleaved caspase-3 (A-C) and NF-KB p65 (D-F) in a normal liver showing negative staining for hepatocytes and Kupffer cells $(A, D)$; in the livers of a severe $P$. falciparum malaria case without hyperbilirubinaemia $(\mathbf{B}, \mathbf{D})$ and with hyperbilirubinaemia $(\mathbf{C}, \mathbf{F})$. Hepatocytes are generally unaffected. Arrows show Kupffer cells lying next to the hepatic cord, within the sinusoidal area. In the normal liver, Kupffer cells are small, non-reactive and rarely express the cleaved caspase-3 marker (A) and show few NF-KB p65 (D) compared with severe $P$. falciparum malaria without hyperbilirubinaemia $\mathbf{( B , E )}$ and with hyperbilirubinaemia $(\mathbf{C}, \mathbf{F})$ where Kupffer cells are enlarged and hyperplastic. Most Kupffer cells containing haemozoin pigment (arrowheads) expressed apoptotic and NF-kB p65 markers. Numerous Kupffer cells show apoptosis (C) and NF-KB p65 expression (F) in severe P. falciparum malaria with hyperbilirubinaemia. All images are at 400x magnification; bars are $20 \mu \mathrm{m}$. 


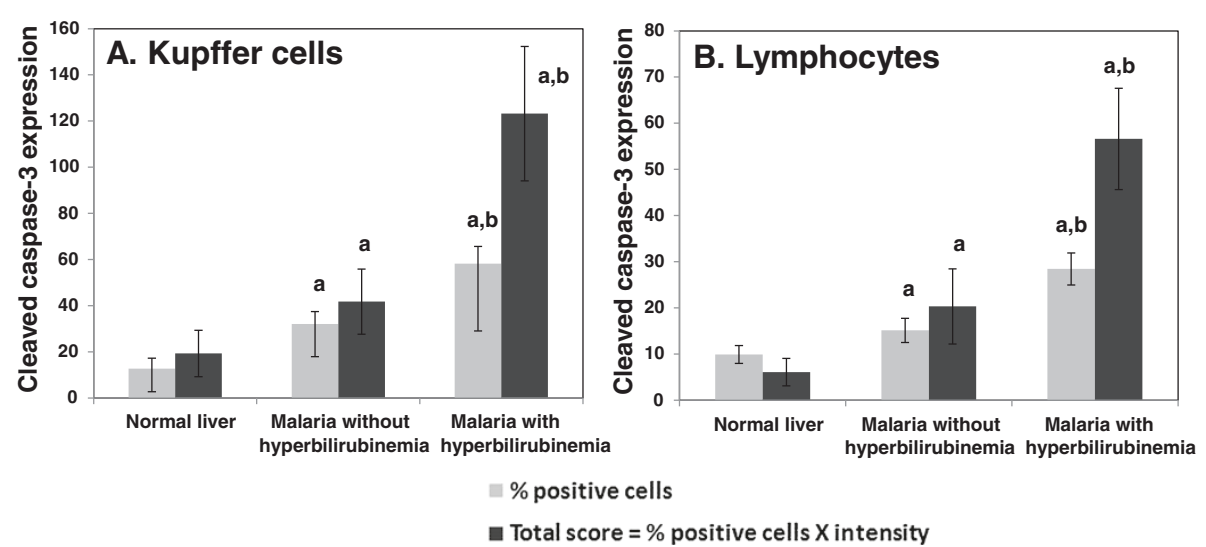

Figure 4 Cleaved caspase-3 expression in Kupffer cells and lymphocytes in the portal tracts. Significant differences were observed between the severe malaria groups (with and without hyperbilirubinaemia) and the normal controls (a), and between the hyperbilirubinaemia and non-hyperbilirubinaemia groups (b) $(p<0.05)$, in both percentage and total scores for cleaved caspase-3 expression in Kupffer cells (A) and lymphocytes in the portal tracts (B). Data are presented as mean \pm SEM.

noted here was similar to a previous finding [5]. Liver cell necrosis in P. falciparum was not a striking finding in this study. It has also been reported as a rare event in some other studies $[5,18]$. However, the incidence of hepatic necrosis may be as high as 41\% [4] and severe cases of centrizonal necrosis have been documented [18]. This change has been reported to be secondary to suppression of bilirubin excretion by PRBCs or metabolic acidosis rather than hepatitis per se [14]. Sequestration of PRBCs is a common finding and depends on malaria parasite load.

\section{Apoptosis and NF-KB p65 in the liver of severe $P$. falciparum malaria cases}

Among various cells evaluated in the liver tissue, Kupffer cells and inflammatory cells show significant apoptotic changes in severe $P$. falciparum malaria. Hepatocytes, bile ducts and ECs failed to show significant apoptotic changes. $P$. falciparum has been shown to induce apoptosis in human cells, such as in lymphocytes [13,20-22], neurons [13], glial cells [13], brain ECs [13] and lung ECs [23]. This may be responsible for clinical manifestations and progression to severe disease. In animal models, malaria-induced apoptosis was evident in astrocytes [24], lymphocytes [25], liver and spleen [8,25]. During the liver stage, however, hepatocytes are usually spared from the apoptotic process, allowing merozoites to be released into the circulation, suggesting that malaria sporozoites can block pro-apoptotic pathways [26]. The present study focuses on liver changes in the erythrocytic stage, which is far beyond the liver stage of

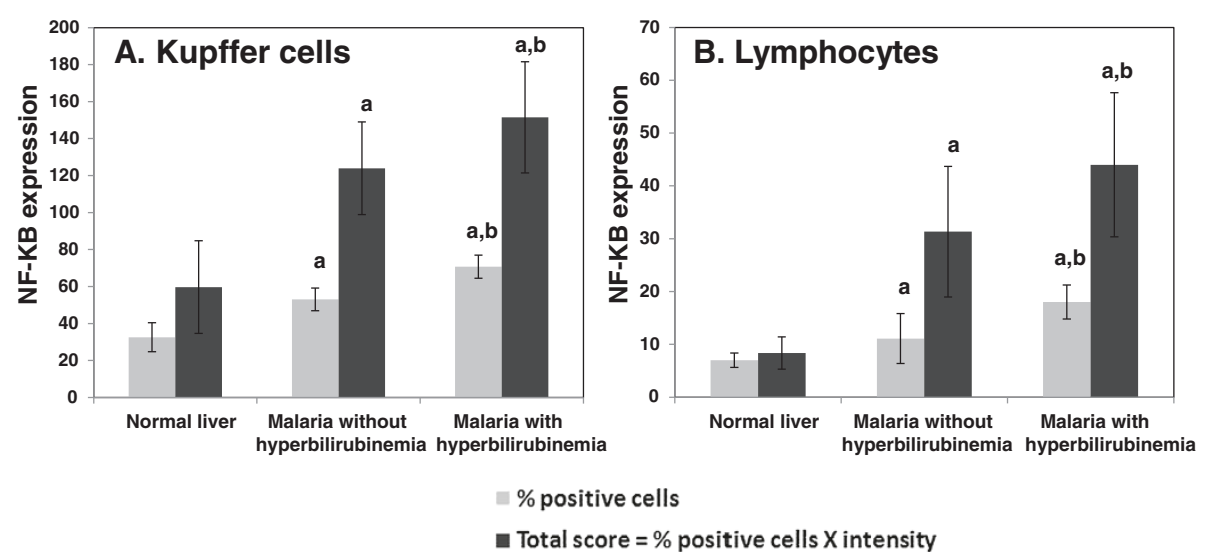

Figure 5 NF-KB p65 expression in Kupffer cells and lymphocytes in the portal tracts. Significant differences in percentage and total score for NF-KB p65 expression were observed in Kupffer cells (A) and lymphocytes in the portal tracts (B) between the severe malaria groups (with and without hyperbilirubinaemia) and the normal controls (a) and between the hyperbilirubinaemia and non-hyperbilirubinaemia groups (b) $(p<0.05)$. Data are presented as mean \pm SEM. 


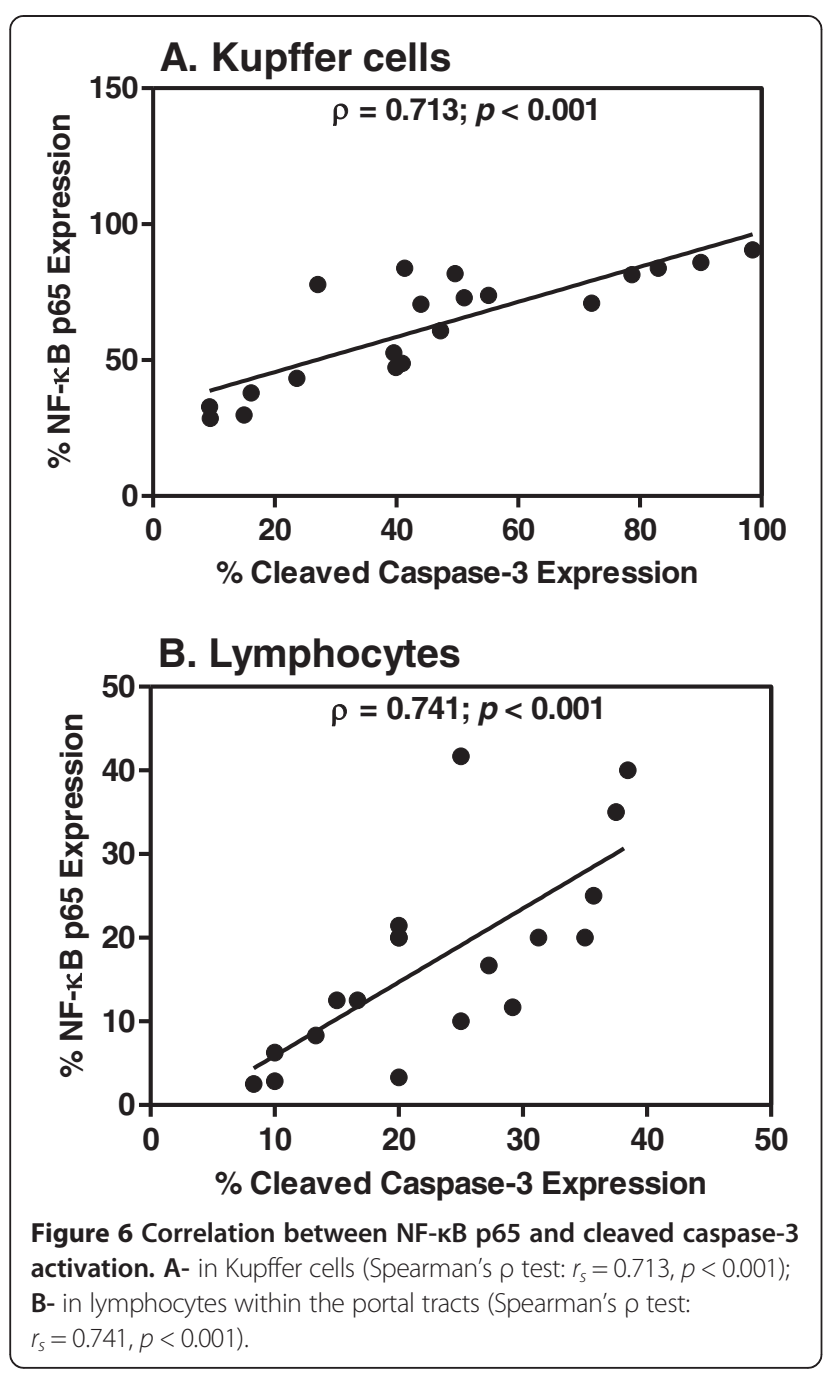

parasite development. Nevertheless, hepatocytes remain morphologically unaffected and protected from apoptosis. Hepatocytes are defended by a barrier of Kupffer cells, endothelial cells, stellate cells, space of Disse (perisinusoidal space) and Kupffer cells. Moreover, PRBCs localized within the sinusoidal area are in close contact with Kupffer cells, the first-line immune defense in the liver. Recognized as foreign bodies, PRBCs and haemozoin are primarily engulfed by the Kupffer cells. In contrast, apoptosis in the hepatocytes has been reported in animal models, linked to activation of the mitochondrial pathway, release of reactive oxygen species $[7,8]$ and induction by glycosylphophatidylinositol (GPI), a major membrane-associated protein of P. falciparum [27].

Apoptosis in the Kupffer cells was evidenced by strong caspase-3 expression. The loaded haemozoin within the cytoplasm of Kupffer cells can be toxic to these immune cells. In humans, during the erythrocytic stage, malaria parasites degrade haemoglobin to produce haem and haemozoin which are harmful. Haemozoin can be deposited in the liver and primarily phagocytized by Kupffer cells, where it can induce oxidative stress [7], a possible mechanism for the induction of apoptosis in Kupffer cells. During the liver stage, Kupffer cell apoptosis has also been detected in a murine model after incubation with Plasmodium yoelii sporozoites [9]. Apoptosis in malaria is reportedly mediated by the Fas-ligand in lymphocytes [20] and in murine astrocytes [24].

$\mathrm{NF}-\mathrm{KB}$ has been shown to regulate various cellular processes such as inflammation, immunity, cell proliferation and apoptosis [28]. A previous study documented $\mathrm{NF}-\mathrm{\kappa B}$ activation and pro-inflammatory response in human brain ECs exposed to PRBCs [29]. A recent study of human brain tissues has demonstrated that $N F-\kappa B$ is one of the signaling molecules that modulates apoptosis in brain ECs and intravascular leukocytes in fatal cerebral malaria [13]. The present study documented NF- $\mathrm{kB}$ mediating apoptosis in Kupffer cells and lymphocytes within the portal tract in severe $P$. falciparum infection.

\section{Conclusions}

Histopathological changes in the livers of severe $P$. falciparum malaria cases are associated with total bilirubin levels. Apoptosis of Kupffer cells and portal tract lymphocytes is a significant finding and is related to NF- $\mathrm{kB}$ activation.

Competing interests

The authors declare that they have no competing interests.

Authors' contributions

PV initiated the research idea, designed the experiments, evaluated histopathology and immunohistochemistry work, supervised, and revised the manuscript. VK retrieved formalin-fixed specimens, performed the histopathology techniques and drafted the manuscript. CP participated in the study design, carried out the immunohistochemical work, preliminary data analysis and manuscript preparation. All authors have approved the final version of the manuscript.

\section{Acknowledgements}

The study was funded by research grants from the Office of the Higher Education Commission and Mahidol University under the National Research Universities (NRU) Initiative, Thailand (by PV) and the Faculty of Tropical Medicine, Mahidol University, year 2011 (by VK). We thank Dr. Mario Riganti for his generous guidance and fruitful suggestions. Help from the staff at the Department of Tropical Pathology, Faculty of Tropical Medicine, Mahidol University, Thailand is highly appreciated.

\section{Author details}

${ }^{1}$ Department of Tropical Pathology, Faculty of Tropical Medicine, Mahidol University, 420/6 Rajvithi Road, Bangkok 10400, Thailand. ${ }^{2}$ Center for Emerging and Neglected Infectious Diseases, Mahidol University, Salaya, Nakhon Pathom 73170, Thailand. ${ }^{3}$ School of Medicine, Walailak University, 222, Thasala District, Nakhon Si Thammarat 80161, Thailand.

Received: 19 December 2013 Accepted: 11 March 2014

Published: 17 March 2014 


\section{References}

1. White NJ: The treatment of malaria. N Engl J Med 1996, 335:800-806.

2. Anand AC, Ramji C, Narula AS, Singh W: Malarial hepatitis: a heterogeneous syndrome? Natl Med J India 1992, 5:59-62.

3. Mehta SR, Naidu G, Chandar V, Singh IP, Johri S, Ahuja RC: Falciparum malaria-present day problems. An experience with 425 cases. J Assoc Physicians India 1989, 37:264-267.

4. Rupani $A B$, Amarapurkar $A D$ : Hepatic changes in fatal malaria: an emerging problem. Ann Trop Med Parasitol 2009, 103:119-127.

5. Whitten R, Milner DA Jr, Yeh MM, Kamiza S, Molyneux ME, Taylor TE: Liver pathology in Malawian children with fatal encephalopathy. Hum Pathol 2011, 42:1230-1239.

6. Prommano $\mathrm{O}$, Chaisri U, Turner GD, Wilairatana P, Ferguson DJ, Viriyavejakul P, White NJ, Pongponratn E: A quantitative ultrastructural study of the liver and the spleen in fatal falciparum malaria. Southeast Asian J Trop Med Public Health 2005, 36:1359-1370.

7. Dey S, Guha M, Alam A, Goyal M, Bindu S, Pal C, Maity P, Mitra K, Bandyopadhyay $U$ : Malarial infection develops mitochondrial pathology and mitochondrial oxidative stress to promote hepatocyte apoptosis. Free Radic Biol Med 2009, 46:271-281.

8. Guha M, Kumar S, Choubey V, Maity P, Bandyopadhyay U: Apoptosis in liver during malaria: role of oxidative stress and implication of mitochondrial pathway. FASEB J 2006, 20:1224-1226.

9. Klotz C, Frevert U: Plasmodium yoelii sporozoites modulate cytokine profile and induce apoptosis in murine Kupffer cells. Int J Parasitol 2008, 38:1639-1650.

10. Thompson CB: Apoptosis in the pathogenesis and treatment of disease. Science 1995, 267:1456-1462.

11. Thornberry NA: Caspases: key mediators of apoptosis. Chem Biol 1998, 5:R97-103.

12. Shishodia S, Aggarwal BB: Nuclear factor-kappaB: a friend or a foe in cancer? Biochem Pharmacol 2004, 68:1071-1080.

13. Punsawad C, Maneerat $Y$, Chaisri U, Nantavisai K, Viriyavejakul P: Nuclear factor kappa B modulates apoptosis in the brain endothelial cells and intravascular leukocytes of fatal cerebral malaria. Malar J 2013, 12:260.

14. Anand AC, Puri P: Jaundice in malaria. J Gastroenterol Hepatol 2005 20:1322-1332

15. World Health Organization: Severe falciparum malaria: Communicable Diseases Cluster. Trans R Soc Trop Med Hyg 2000, 94(Suppl 1):S1-S90.

16. Srivastava A, Khanduri A, Lakhtakia S, Pandey R, Choudhuri G: Falciparum malaria with acute liver failure. Trop Gastroenterol 1996, 17:172-174.

17. Chawla LS, Sidhu G, Sabharwal BD, Bhatia KL, Sood A: Jaundice in Plasmodium falciparum. J Assoc Physicians India 1989, 37:390-391.

18. Joshi YK, Tandon BN, Acharya SK, Babu S, Tandon M: Acute hepatic failure due to Plasmodium falciparum liver injury. Liver 1986, 6:357-360.

19. Chua CL, Brown G, Hamilton JA, Rogerson S, Boeuf P: Monocytes and macrophages in malaria: protection or pathology? Trends Parasitol 2013, 29:26-34.

20. Riccio EK, Junior IN, Riccio LR, das Gracas Alecrim M, Corte-Real S, Morgado M, Daniel-Ribeiro CT, de Fatima Ferreira-da-Cruz M: Malaria associated apoptosis is not significantly correlated with either parasitemia or the number of previous malaria attacks. Parasitol Res 2003, 90:9-18.

21. Balde AT, Sarthou JL, Roussilhon C: Acute Plasmodium falciparum infection is associated with increased percentages of apoptotic cells. Immunol Lett 1995, 46:59-62.

22. Toure-Balde A, Sarthou JL, Aribot G, Michel P, Trape JF, Rogier C, Roussilhon C: Plasmodium falciparum induces apoptosis in human mononuclear cells. Infect Immun 1996, 64:744-750.

23. Pino P, Vouldoukis I, Kolb JP, Mahmoudi N, Desportes-Livage I, Bricaire F, Danis M, Dugas B, Mazier D: Plasmodium falciparum-infected erythrocyte adhesion induces caspase activation and apoptosis in human endothelial cells. J Infect Dis 2003, 187:1283-1290.

24. Potter SM, Chan-Ling T, Rosinova E, Ball HJ, Mitchell AJ, Hunt NH: A role for Fas-Fas ligand interactions during the late-stage neuropathological processes of experimental cerebral malaria. J Neuroimmunol 2006, 173:96-107.

25. Helmby H, Jonsson G, Troye-Blomberg M: Cellular changes and apoptosis in the spleens and peripheral blood of mice infected with blood-stage Plasmodium chabaudi chabaudi AS. Infect Immun 2000, 68:1485-1490.

26. van de Sand C, Horstmann S, Schmidt A, Sturm A, Bolte S, Krueger A, Lutgehetmann M, Pollok JM, Libert C, Heussler VT: The liver stage of Plasmodium berghei inhibits host cell apoptosis. Mol Microbiol 2005, 58:731-742
27. Wichmann D, Schwarz RT, Ruppert V, Ehrhardt S, Cramer JP, Burchard GD, Maisch B, Debierre-Grockiego F: Plasmodium falciparum glycosylphosphatidylinositol induces limited apoptosis in liver and spleen mouse tissue. Apoptosis 2007, 12:1037-1041.

28. Li Q, Verma IM: NF-kappaB regulation in the immune system. Nat Rev Immunol 2002, 2:725-734.

29. Tripathi AK, Sha W, Shulaev V, Stins MF, Sullivan DJ Jr: Plasmodium falciparuminfected erythrocytes induce NF-kappaB regulated inflammatory pathways in human cerebral endothelium. Blood 2009, 114:4243-4252

doi:10.1186/1475-2875-13-106

Cite this article as: Viriyavejakul et al:: Liver changes in severe Plasmodium falciparum malaria: histopathology, apoptosis and nuclear factor kappa B expression. Malaria Journal 2014 13:106

\section{Submit your next manuscript to BioMed Central and take full advantage of:}

- Convenient online submission

- Thorough peer review

- No space constraints or color figure charges

- Immediate publication on acceptance

- Inclusion in PubMed, CAS, Scopus and Google Scholar

- Research which is freely available for redistribution

Submit your manuscript at www.biomedcentral.com/submit
C Biomed Central 